\title{
НЕГОСУДАРСТВЕННОЕ ПЕНСИОННОЕ ОБЕСПЕЧЕНИЕ КАК ФОРМА ПРОЯВЛЕНИЯ КОРПОРАТИВНОЙ СОЦИАЛЬНОЙ ОТВЕТСТВЕННОСТИ И МОТИВАЦИОННЫЙ РЕСУРС В УПРАВЛЕНИИ ПЕРСОНАЛОМ ОРГАНИЗАЦИИ
}

\section{PRIVATE PENSION PROVISION AS A FORM OF APPEARANCE IN CORPORATE SOCIAL RESPONSIBILITY AND A MOTIVATIONAL RESOURCE IN PERSONNEL MANAGEMENT}

E. Valishin

Summary. The author analyzes the features of corporate social responsibility in foreign business practices. Non-state pension funds and their motivational potential for managing the organization's personnel are considered by way of example of corporate social responsibility of business in Russia. It gives a detailed analysis of a concept of trusting in the pension program and private pension funds (NPFs), as well as the responsibility of the funds themselves for investing money of depositors to ensure profitability. Pension market participants are noted in the asset management (Russian Pension Fund, insurance companies, private pension funds) have the opportunity to act as a medium-term financing source. It should be stressed that, it is provided examples from the practice of pension funds, as well as ways to incorporate corporate social responsibility in the main areas of activity of joint-stock companies. The possibilities and features of the activation of motivational resources in the process of development of pension programs are discussed.

Keywords: corporate social responsibility, non-state pension funds, dissemination of the principle of responsible investment, social responsibility of business, motivational management, motivational resources.

\author{
Валишин Евгений Николаевич \\ К.nсх.н., доцент, Финансовый университет при \\ Правительстве Российской Федерации \\ ewgeni-v@rambler.ru
}

Аннотация. Автором анализируются особенности корпоративной социальной ответственности в зарубежной практике ведения бизнеса. В качестве примера корпоративной социальной ответственности бизнеса в России рассматриваются негосударственные пенсионные фонды, и их мотивационный потенциал для управления персоналом организации. Затронуты вопросы, связанные с доверием к пенсионным программам и негосударственным пенсионным фондам (НПФ), а также ответственность самих фондов за вложение денежных средств вкладчиков по обеспечению доходности. Участники пенсионного рынка управления активами (пенсионный фонд России, страховые компании, частные пенсионные фонды) имеют возможность выступить в качестве источника среднесрочного финансирования. В статье приводятся примеры из практики пенсионных фондов, а также способы включения корпоративной социальной ответственности в основные направления деятельности акционерных обществ. Рассматривается возможности и особенности активизации мотивационных ресурсов в процессе развития пенсионных программ.

Ключевые слова: корпоративная социальная ответственность, негосударственные пенсионные фонды, распространение принципа ответственного инвестирования, социальная ответственность бизнеса, мотивационное управление, мотивационные ресурсы.
$\Pi$ роцесс развития современной России показывает, что успех в развитии социально-экономических систем зависит не только от политических и экономических, но и от психологическими и социально-психологическими факторов. Не владея реальной картиной об активных, значимых потребностях населения, экономических субъектов, т.е. если отсутствует в должно мере мотивированное доверие и поддержка, невозможно осуществить реализацию выработанной стратегии развития. Подтверждением этого является отрицательная реакции определенных категорий активного населения на реализацию положений пенсионной реформы на практике. В современных условиях управление социально-экономическими системами с учетом мотивационно потенциала работников, делает акцент не только на особенности поведения отдельного человека или группы, но и особенно на влияние мотивационных установок на результаты деятельности социально-экономических систем (национальных, региональных, муниципальных, транснациональных корпораций и других крупных организационных систем). Использование мотивационных ресурсов в управление социально-экономическими системами является важной и интенсивно развивающейся практикой.

Важнейшим признаком цивилизованности современного бизнеса выступает его социальная ориентированность. Социальная ответственность бизнеса - от- 
ветственность субъектов бизнеса за соблюдение норм и правил, неявно определенных или не определенных законодательством (в области этики, экологии, милосердия, человеколюбия, сострадания и т.д.), влияющих на качество жизни отдельных социальных групп и общества в целом. Социальная ответственность бизнеса — это осознанное поведение бизнеса направленное на развитие экономической, социальной и экологической сфер общества, связанное с основной деятельностью компании и выходящий за рамки определенного законом минимума, но эта трактовка является довольно идеальным и не может быть полностью воплощено в реальность хотя бы потому, что просто невозможно рассчитать все последствия одного решения [1]. Социальная ответственность скорее не правило, а этический принцип, который должен быть реализован при принятии решений. Соответственно ответственность здесь внутренняя, перед собой и должна основываться на моральных ценностях, которые приобретаться в процессе социализации. Корпоративная социальная ответственность, особенно в области прав работников, служит руководством для дальнейшего роста и развития компании, в то же время принимая во внимание социальные, экологические и другие составляющие. Кроме этого, следует не забывать и об удовлетворении потребностей не только сотрудников, но и акционеров, что, в свою очередь, безусловно, будет способствовать росту компании, а также соответствующему увеличению стоимости доли, которая непосредственно стимулирует развитие корпоративной социальной ответственности.

В рамках существующих рыночных отношений сегодня, негосударственные пенсионные фонды зачастую представляют крупные акционерные общества, что создает возможность их решающего влияния в качестве главных действующих лиц рынка при принятии решений, связанных с корпоративной социальной ответственностью.

Социальная ответственность корпорации делится на внутреннюю и внешнюю. Страны с развитой рыночной экономикой демонстрируют растущий интерес к корпоративной социальной ответственности (КСО), о чем свидетельствует обширная теоретическая и эмпирическая литература по этому вопросу. В ней делается вывод о том, что КСО не следует рассматривать как привилегию развитых стран с рыночной экономикой, поскольку в организациях центральной и восточной Европы существует множество примеров. Тем не менее, изучение их специфики представляется более сложным вопросом. Эволюционный подход к институтам КСО позволяет нам считать, что анализ форм КСО в контексте стран с переходной экономикой должен учитывать взаимодействие между элементами, зависящими от прошлого, а также со стандартами и практикой уже существующих в разви- тых странах. Так уже, Берл и Минс в 1933 году, Барнард в 1938 году, писали, что ответственность деловых людей и этические обязанности менеджеров стали одной из центральных тем в организационных исследованиях в США. С 1990-х годов концепция корпоративной социальной ответственности (КСО) приобретает все большую популярность и в Западной Европе. Идея «экономики заинтересованных сторон» была выдвинута в Великобритании с момента создания «CSR Europe» в 1995 году. В Зеленой книге, опубликованной Европейской комиссией в 2001 году, КСО была определена как «концепция, через которую компании интегрируют экологические и социальные проблемы в собственные бизнес-технологии и во взаимодействие с заинтересованными сторонами на добровольной основе». Другими словами, «быть социально ответственным означает не только оправдывать законные ожидания, но и выходить за рамки соблюдения и вкладывать «больше» в человеческий капитал, окружающую среду и отношения с заинтересованными сторонами» [8]. Тем не менее, необходимо отметить, что в прошлом, как и сегодня, КСО означает что-то, но не всегда одно и то же, для всех вероятно существует объяснение этого отсутствия консенсуса. Во-первых, иногда КСО является лишь концепцией социального маркетинга, которая заботится об их публичном имидже, но избегает каких-либо подлинных изменений или, что еще хуже, управляется деловыми людьми, свободными от чувства моральной ответственности, что конечно, способствует дискредитации концепции и ограничению ее простой риторикой. Во-вторых, термин «корпоративная социальная ответственность» не обязательно имеет то же значение в континентальных европейских или азиатских традициях, что и в англо-американском контексте «минимальному поведенческому стандарту в отношении взаимоотношений корпорации с заинтересованными сторонами». Так считается, что те компании, которые делают две вещи, являются социально ответственными: «Во-первых, они не обязаны сознательно делать что-то, что может нанести ущерб их заинтересованным сторонам, в частности, инвесторам, работникам, клиентам, поставщикам или местному сообществу, в котором они работают. Во-вторых, если компании наносят ущерб своим заинтересованным сторонам, они обязаны устранять это всякий раз, когда ущерб выявлен и доведен до их сведения» [6]. Это определение может привести нас к предположению, что практики, которые будут оцениваться как нормальные или как основные деловые практики выполнения своих обязанностей в западном контексте, могут казаться ответственными, моральные или этические в других местах или в другое время по сравнению с обычной деловой практикой. Если рассматривать систему KCO, то можно говорить о существовании трех основных подходов к КСО: бизнес и этика; бизнес и общество; управление социальными вопросами. Они были сформулированы в США, но оказали влияние и на мно- 
гие другие развитые страны с рыночной экономикой. Кратко рассмотрим эти подходы в свете их степени интеграции институциональных проблем. Каркас, разработанный Джонсом в 1999 г. является представителем перехода от теории заинтересованных сторон КСО, основанной на договорах между различными заинтересованными сторонами, к более глубокому анализу институционального контекста, в который встроена компания. Он представляет взаимосвязь между конфигурациями институциональных структур на социально-культурном, национальном, промышленном, фирменном и индивидуальном уровнях и необходимыми и достаточными условиями для реализации концепции социальной ответственности на практике. Он утверждает, что более мелкие, тесно связанные фирмы в прибыльных нишах находятся в оптимальном положении, чтобы действовать социально ответственным образом. Однако этих элементов недостаточно. Согласно опросу, проведенному в ВЦИОМ, только 38\% работодателей организуют профессиональную практику, но каждый третий молодой человек видит эту практику как шанс для лучшего позиционирования на рынке труда. Большинство работодателей (54\%), принявших участие в этом исследовании, заявили, что не планируют нанимать новых сотрудников. Работодатели также пытались выявить проблемы с трудоустройством молодежи. Макро- (рост безработицы, структурная безработица, рост стоимости жизни) и микроэкономические аспекты (замораживание найма, низкая заработная плата, увольнения) негативно влияют на работников в России, усиливая сдерживание сотрудников, страх, неуверенность и стресс. Кроме того, лица, принимающие решения в организациях, должны иметь ценности, соответствующие социальной ответственности, а ответственные действия должны восприниматься как институционально законные. Соответствующие институциональные детерминанты должны достигать своего рода порогового уровня, который делает ответственные действия жизнеспособными. В целом, подход к управлению социальными вопросами предоставляет ценные инструменты для понимания взаимодействия бизнеса и его среды, что приводит к появлению практики КСО. Создание и поддержание негосударственного пенсионного обеспечения является одной из форм проявления социальной ответственности бизнеса [2;10].

Пенсионное обеспечение, его социальная значимость определяется его ролью в экономической и социально-политической жизни общества. Пенсионная система зависит от многих факторов и условий, таких как размеры оплаты труда, налоговая система, рынок труда и демографическая ситуация [5]. В настоящее время, на российском пенсионном рынке сложилась ситуация, позволяющая говорить о развитии накопительной части пенсионных схем. Одним из наиболее эффективных механизмов повышения уровня жизни пенсионеров, признанных во всем мире, является развитие частной пенсионной системы. Эта система позволяет привлекать не только государство, но и работодателя, регион, а также граждан к формированию достойного уровня жизни, что сказывается на построении эффективной социальной защиты пенсионеров. Повышение привлекательности домохозяйств для инвестирования средств в частные пенсионные фонды должно привести к тому, что, с одной стороны, частные пенсионные фонды, а с другой стороны, застрахованные лица должны нести солидарную ответственность за свою деятельность. Результаты социологическое исследование среди трудоспособного населения РФ показали низкий уровень информированности населения по различным аспектам развития системы негосударственного пенсионного обеспечения. По результатам опроса можно высказать предположение о достаточно низкой информированности населения об услугах, предоставляемых негосударственными пенсионными фондами. Информированы и скорее информированы 43,1\% всех респондентов, а ничего или скорее не имеют представления об услугах НПФ 56,9\% из числа опрошенных респондентов. Хотя и наблюдается достаточно невысокий уровень осведомленности населения о системе корпоративных пенсий (информированы в общем - 17,6\%), большинство респондентов $(67,2 \%)$ в основном позитивно относятся к идее развития корпоративного пенсионного обеспечения. Всего лишь $17,1 \%$ респондентов не поддерживают идею развитие системы корпоративного пенсионного обеспечения и 15,7\% респондентов - скорее не поддерживают. Количество поддерживающих идею корпоративного пенсионного обеспечения (КПО) незначительно снижается (-2,8\%), однако, на $11 \%$ выросла доля поддерживающих КПО. Так проведенное социальное исследование показало, что отношение респондентов к принципу совместной ответственности государства, работодателя и работника в пенсионной системе в 2019 году практически не изменилось по сравнению с 2015 годом. Как и в предшествующие годы, равный процент респондентов возлагают ответственность за обеспечение достойного уровня пенсии (44\%) [9]. Все это говорит, о росте совместного партнерства всех сторон - государства, работодателя, самого работника, в обеспечении достойного уровня пенсии. Потенциальным результатом внедрения пенсионных моделей должно стать распространение негосударственных пенсионных схем. Негосударственное пенсионное обеспечение (НПО) является элементом российской пенсионной системы и состоит в обеспечении населения негосударственными пенсиями в соответствии с законодательством Российской Федерации на основании договора с негосударственным пенсионным фондом (НРФ). Оно осуществляется на добровольной основе в дополнение к обязательному пенсионному страхованию. Неправительственные организации должны быть внедрены не только в корпорациях, но и в дру- 
гих организациях, что будет способствовать построению полноценной пенсионной системы для населения Российской Федерации. Среди совокупности факторов и условий, определяющих отношение населения к выбору пенсионной модели, ключевая роль принадлежит социальному восприятию людей относительно характера пенсионных выплат, распределению обязанностей между работником, работодателем и государство, чтобы обеспечить достойный уровень пенсии, жизненные стратегии и поведение, чтобы обеспечить дополнительный доход по достижении пенсионного возраста. Все это в совокупности определяет направление поведения конкретного человека, выражающееся в социальных приоритетах и установках на социальное участие в различных видах и формах негосударственного пенсионного обеспечения.

Все большое количество сотрудников входит в корпоративные пенсионные программы, в то же время количество НПФ на рынке сокращается. Этому способствует процесс консолидации Фондов. Процесс слияние приводит к сокращению издержек. Так, в инвестиционной деятельности наблюдается. эффект экономии от масштаба. У топ-10 НПФ по величине пенсионных накоплений в среднем разница доходности инвестирования до и после выплаты вознаграждения управляющим компаниям, специализированному депозитарию и фонду составляет 0,6 п.п.; занимающих места с 11-го по 20е,- 0,7 п.п.; с 21-го по 30-е место - 0,75 п.п.; у последних трех фондов 1,5 процентного пункта [4]. В связи с этим, слияние НПФ повышает эффективность их инвестиционной деятельности.

В современных условиях ведения бизнеса, когда наблюдается высокая динамика социально-экономических изменения, необходимо понимать, что работникам и организациям в этих условиях требуются не только перемены, но и определенная степень стабильности. В связи с этим, одной из основных задач является поиск опре- деленного компромисса между переменами и потребностью в стабильности. Что необходимо сделать, чтобы сформировать определенное отношение работников к пенсионным программам, которое позволило бы им осознанно совершать действия по накоплению пенсионных вложений (как инвестиции в свое будущее, т.к. произойдет изменение их социального статуса). Стоит задача формирования установки к пенсионным накоплениям как к «отсроченному» будущему, когда индивидуальный человеческий капитал изменяется (физический, психический, интеллектуальный, социальный). Рассмотрение пенсионных накоплений как ценностной ориентации требует исследования мотивационно-ценностной структуры работника (место пенсионных накоплений ценностной ориентации в иерархии ценностей экономически активного населения). Исследование специфики пенсионных накоплений как ценностной ориентации на различных этапах профессиональной деятельности и как управлять изменениями в поведении с учетом выявленной специфики. Все это предполагает теоретическое и практическое обеспечения данного процесса на макро и - микроуровнях социально-экономических систем.

Инструменты КСО должны быть включены в бизнес-процессы организации. Реализация пенсионных программ как внутренних инструментов в рамках КСО. На выходе, при управлении персоналом организации: повышение трудовой мотивации персонала (экономическая безопасность, стабильность во второй половине жизни, которая позволит сохранить основные параметры того образа жизни (стиль), который является комфортным для конкретного субъекта труда; удержание высококвалифицированных работников (их развитие и социальное обеспечение); формирование положительного имиджа организации на рынке труда, что может дать дополнительные возможности по снижению бизнес-рисков, связанных с нехваткой высококвалифицированных работников с высоким потенциалом развития («таланты»).

\section{ЛИТЕРАТУРА}

1. Федеральный закон от 26 июля 2019 г. N245-Ф3»0 внесении изменений в Федеральный закон «0 развитии малого и среднего предпринимательства в Российской Федерации» в части закрепления понятий «социальное предпринимательство», «социальное предприятие» [http://www.consultant.ru/document/ cons_doc_LAW_329995/].

2. Валишина М.Е., Валишин Е. Н. НПФ как участник инвестиционного процесса в инфраструктурных проектах и их социальная ответственность // Современная наука: актуальные проблемы теории и практики. Серия «Экономика и Право»,_ 2019, -№ 6, -с. 81-84.

3. Валишин Е. Н. Мотивационные ресурсы организации для инновационной среды // В сборнике: Формирование общекультурных и профессиональных компетенций финансиста. Москва, 2017. С. 60-65.

4. Обзор ключевых показателей негосударственных пенсионных фондов [В Интернете]. ЦБ РФ,2020 г. https://cbr.ru/collection/collection/file/23997/rewiew_ npf_19q3.pdf.

5. Перспективы развития негосударственного пенсионного обеспечения: монография / Солдатов А.А., Бабакаев С. В., Батаев В. В., Каурова 0. В., Малолетко А. Н., Починок Н. Б., Кулямина 0.С., Виноградова М. В. — Москва: Русайнс, 2016. — 223 c.— ISBN978-5-4365-1249-5. — URL: https://book.ru/ book/921642 (дата обращения: 26.03.2020). 
6. Управление рисками организации. Интегрированная модель. (COSO ERM). The Committee of Sponsoring Organizations of the Treadway Commission (COSO). [B Интернете].—26 022020 r._- http://www.coso.org/documents/coso_erm_executivesummary_rus sian.pdf.

7. Forum Nachhaltige Entwicklung der Deutschen Wirtschafteconsense.de/en UR — http://www.econsense.de/en (дата обращения: 26.2.2019)

8. The European Business Network for Corporate Social Responsibility http://www.csreurope.org (дата обращения: 26.02.2018)

9. OECD Development Cooperation Report 2016: The Sustainable Development Goals as Business Opportunities. Paris: OECD Publishing, 2016.316 p, c55-57

10. ВЦИОМ, 2020. ВЦИОМ: Доходы и инвестиции: развивать и контролировать. [В Интернете] Available at: https://wciom.ru/index.php?id=212\&uid=9805 Дата обращения: 26 январь 2020

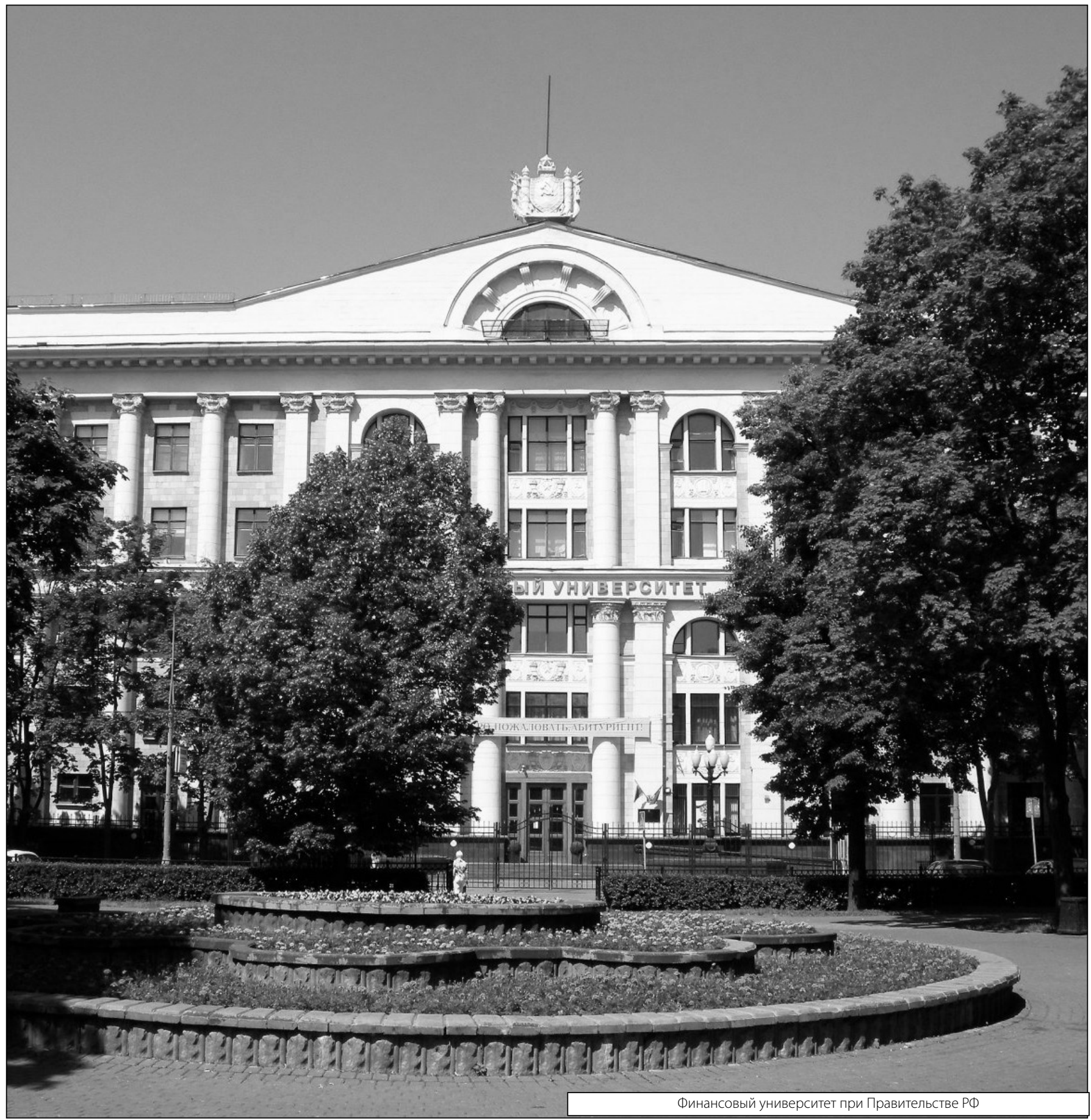

